\title{
Perfil dos Incêndios em Vegetação nos Municípios de Juiz de Fora e Ubá, MG, de 2001 a 2007
}

\author{
Fillipe Tamiozzo Pereira Torres ${ }^{1,2}$, Guido Assunção Ribeiro ${ }^{1}$, \\ Sebastião Venâncio Martins ${ }^{1}$, Gumercindo Souza Lima ${ }^{1}$ \\ ${ }^{1}$ Departamento de Engenharia Florestal, Universidade Federal de Viçosa - UFV
}

${ }^{2}$ Faculdade de Filosofia, Ciências e Letras, Universidade Presidente Antônio Carlos - UNIPAC

\begin{abstract}
RESUMO
O Objetivo deste trabalho é traçar um perfil dos incêndios em vegetação em 2 municípios mineiros: Juiz de Fora e Ubá. Foi analisada uma série temporal entre 2001 e 2007, analisando a quantidade de ocorrências, época do ano e horário de maior concentração de incêndios, vegetação atingida e exposição da vertente das ocorrências. De acordo com os resultados. Os meses entre junho e outubro foram os mais problemáticos e o horário entre 12 e 16 horas apresentou maior risco. A vegetação herbácea foi mais atingida nos dois municípios e a exposição da vertente influenciou decisivamente nas ocorrências de incêndios.
\end{abstract}

Palavras-chave: incêndios, comportamento, perfil.

\section{Vegetation Fire Statistics in the Municipalities of Juiz de Fora and Ubá, State of Minas Gerais, Brazil, from 2001 to 2007}

\begin{abstract}
The objective of this work is to draw a profile of vegetation fire in 2 municipalities of the State of Minas Gerais: Juiz de Fora and Uba. A temporary series was analyzed between 2001 and 2007, concerning the amount of occurrences, the time of the year and the time schedule of larger concentration fires that attacked vegetation, as well as the exhibition of the slope of occurrences. According to the results, the time period between June and October were the most problematic and the time schedule between 12:00 PM and 4:00 PM presented larger risks. The herbaceous vegetation was more attacked in the two municipalities and the exhibition of the slope influenced decisively in the occurrences of fires.
\end{abstract}

Keywords: vegetation fire, behavior, statistics. 


\section{INTRODUÇÃO}

De acordo com Soares (1995), o fogo é um fenômeno natural que sempre existiu na superfície do planeta é também um dos responsáveis pela predominância de vários ecossistemas terrestres.

Para Ribeiro e Bonfim (2000), o fogo é uma reação química exotérmica envolvendo três elementos básicos: combustível, oxigênio e calor. Assim, é necessário haver combustível para queimar, oxigênio para manter as chamas e calor para iniciar e continuar o processo de queima. A ausência, ou redução abaixo de certos níveis de qualquer um dos componentes do triângulo do fogo, inviabiliza o processo de combustão.

Contudo, a ação do fogo sobre o ambiente depende, ainda, de outros fatores além dos necessários para a ocorrência da combustão. De acordo com Batista (1995) e Ribeiro e Bonfim (2000), vários fatores afetam e influem no comportamento do fogo, entre eles: o material combustível; as condições climáticas; e a topografia. A ação de cada um destes fatores é diferente para cada região e para cada época do ano, o que causa grande diferença em seu comportamento.

Entretanto, não basta que os fatores diretamente associados à ocorrência dos incêndios em vegetação estejam favoráveis. Para que um incêndio ocorra é necessária a chama inicial para dar início ao processo da combustão. Assim, qualquer ação para prevenção dos incêndios deve buscar a eliminação de suas causas.

Desde os primórdios, o homem emprega o fogo objetivando a limpeza do terreno e o seu manejo para a pecuária e a agricultura. É fato que o uso do fogo é uma prática comum no meio rural, por ser uma técnica eficiente sob o ponto de vista dos produtores (Bonfim et al., 2003).

Quando o comportamento do fogo foge do controle do homem, transformando-o em um agente com alto poder destrutivo, tem-se o incêndio propriamente dito (Silva et al., 2003). Diferenciando-o, por exemplo, da queima controlada que significa o uso do fogo de forma planejada, com objetivos definidos, acompanhado de um planejamento prévio em que devem ser considerados os aspectos legais (autorização de queima), as técnicas de queima, as condições climáticas, a previsão do comportamento do fogo, os equipamentos e as ferramentas apropriadas e os confrontantes (Ribeiro e Bonfim, 2000).

Para Torres et al. (2008), o próprio conceito de incêndio florestal acaba por gerar algumas contradições, visto que é utilizado como sinônimo de fogo sem controle sobre qualquer tipo de vegetação, seja ela pasto, campo ou floresta. Contudo, o termo floresta, de acordo com o IBGE (Instituto..., 2004) se refere ao conjunto de sinúsias dominadas por fanerófitos de alto porte, e apresentando quatro estratos bem definidos: herbáceo, arbustivo, arvoreta e arbóreo. Deve ser também levada em consideração a altura, para diferenciá-la das outras formações lenhosas campestres. Para Rizzini (1979), a definição de floresta ou mata é sempre que as árvores superem $7 \mathrm{~m}$ de altura e toquem-se pelas copas.

Apesar de usual o termo de incêndios florestais, dentro do meio científico, o leitor menos familiarizado, pode-se questionar quanto à sua utilização em uma área de pasto ou campo com vegetação aberta. Sendo assim, neste estudo, sugerem-se as seguintes denominações:

- Incêndio florestal: quando ocorrer em áreas com predomínio de espécies arbóreas, sejam elas plantadas ou nativas;

- Incêndio em campo: quando ocorrer em áreas de pasto ou campo com predomínio de vegetação herbácea e/ou arbustiva; e

- Incêndio em vegetação: termo generalista utilizado quando ocorrer em qualquer tipo de vegetação, seja ela herbácea, arbustiva ou arbórea.

Os incêndios em vegetação geram diversos prejuízos econômicos, paisagísticos e ecológicos, podendo ocorrer em Unidades de Conservação, áreas de preservação, fazendas, margens de estradas, proximidades de aglomerados urbanos e áreas de reflorestamento, dentre outras localidades (Fiedler et al., 2006).

Soares e Santos (2002) afirmam que, para se estabelecer uma política adequada de prevenção de incêndios, é necessário conhecer as estatísticas referentes a eles, isto é, saber onde, quando, e porquê eles ocorrem. A falta dessas informações pode levar a um dos dois extremos: gasto muito alto, acima do potencial de danos ou gasto muito baixo, colocando 
em risco a sobrevivência da vegetação e das pessoas envolvidas.

É fundamental, de acordo com os autores, saber onde ocorrem os incêndios para a determinação das áreas de maior risco, estabelecendo programas específicos para estas regiões. Também se torna necessário saber quando ocorrem para se estruturar os serviços de prevenção e combate dentro de limites economicamente viáveis, ativando o sistema durante os períodos críticos e desativando-os nos meses de menor risco. Finalmente, é preciso conhecer as principais causas dos incêndios para se fazer um trabalho objetivo de prevenção, visando a redução daquelas causas mais frequentes.

De acordo com estudos sobre o perfil dos incêndios em vegetação no Brasil, no período de 1994 a 1997 (Soares e Santos, 2002) e de 1998 a 2002 (Santos et al., 2006), Minas Gerais foi o Estado com maior número de ocorrências registradas, seguido pelos estados do Espírito Santo e de São Paulo. Com relação à área queimada, o Estado de Minas também ocupou o primeiro lugar, seguido pelos estados de São Paulo e da Bahia.

Dentro deste contexto, o objetivo deste trabalho é traçar o perfil das ocorrências de incêndios em vegetação em 2 municípios da Zona da Mata mineira: Juiz de Fora e Ubá.

\section{MATERIAL E MÉTODOS}

Os municípios de Juiz de Fora e de Ubá localizamse na Zona da Mata mineira (Figura 1), estando os centros das cidades nas coordenadas $21^{\circ} 41^{\prime}$ $20^{\prime \prime}$ S e $43^{\circ} 20^{\prime} 40^{\prime \prime} \mathrm{W} ; 21^{\circ} 07^{\prime} 12^{\prime \prime} \mathrm{S}$ e $42^{\circ} 56^{\prime} 32^{\prime \prime} \mathrm{W}$, respectivamente, distanciando-se cerca de $100 \mathrm{~km}$.

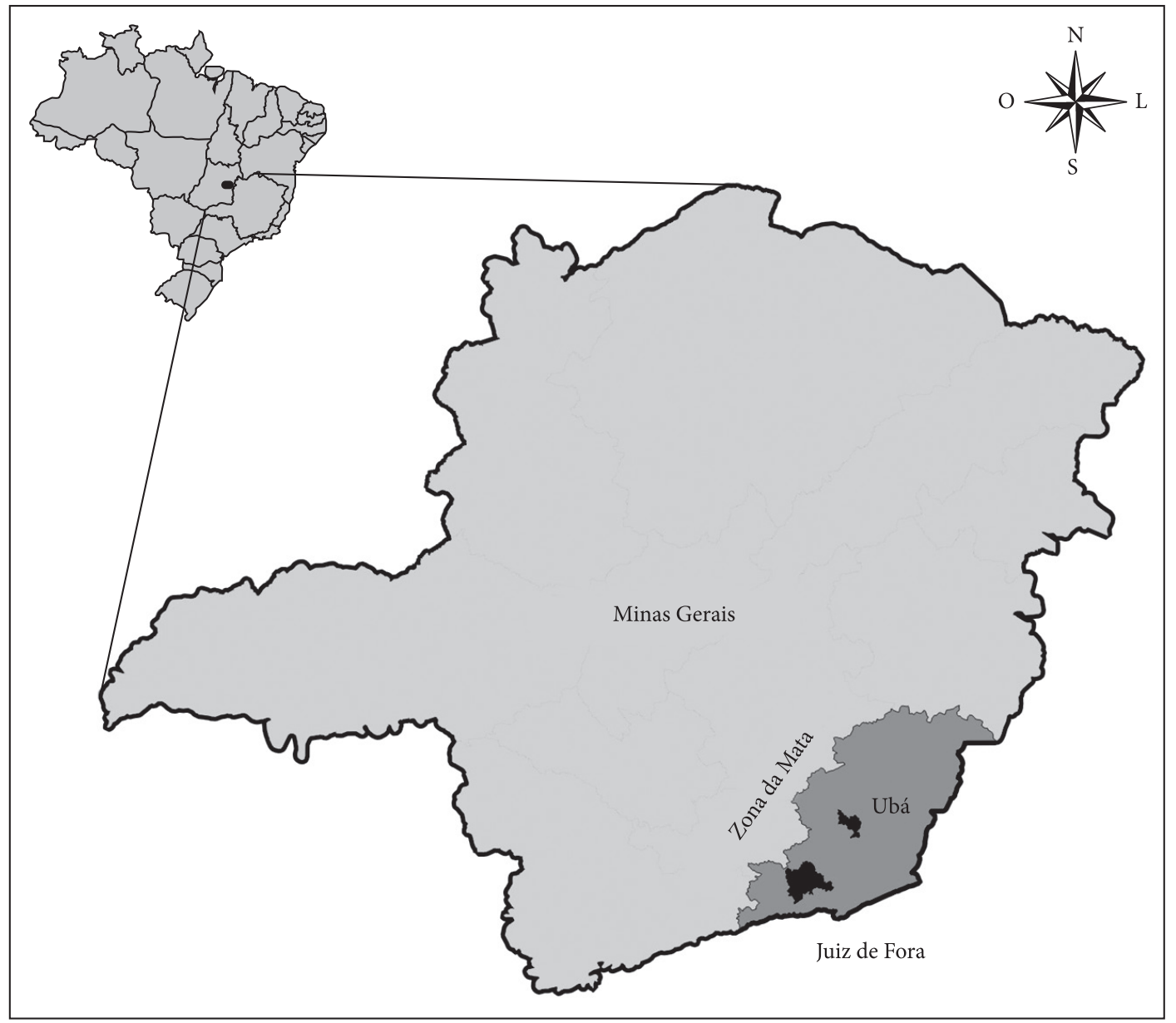

Figura 1. Localização da área de estudo.

Figure 1. Study area location. 
Ambas inseridas no domínio morfoclimático dos mares de morros florestados, possuem um clima tropical, com verão chuvoso e estação seca no inverno, diferenciando-se pela temperatura média mais baixa no município de Juiz de Fora, graças à maior altitude em relação ao nível do mar (684 m contra $343 \mathrm{~m}$ do município de Ubá).

Como área de estudo, foram definidas a área urbana do distrito sede de Juiz de Fora com cerca de $405 \mathrm{~km}^{2}$ (28\% da área total municipal) e o distrito sede de Ubá com $235 \mathrm{~km}^{2}$ ( $58 \%$ da área total municipal).

Os dados foram fornecidos pelo $4^{\circ}$ Batalhão de Bombeiros Militares ( $\left.4^{\circ} \mathrm{BBM}\right)$ através da

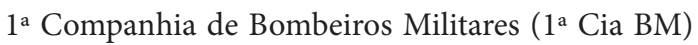
em Juiz de Fora e $3^{\text {a }}$ Cia BM em Ubá. Os dados apresentam a cobertura da queimada, data, endereço e hora de cada ocorrência.

De posse do endereço de cada ocorrência, foi determinada qual a vertente em que ocorreram; e a análise foi feita com idas a campo para sua confirmação. A determinação das vertentes foi feita com a utilização de bússola de acordo com os pontos cardeais, divididas em Norte $\left(316^{\circ}\right.$ a $\left.45^{\circ}\right)$, Leste $\left(46^{\circ}\right.$ a $\left.135^{\circ}\right)$, Sul $\left(136^{\circ}\right.$ a $\left.225^{\circ}\right)$ e Oeste $\left(226^{\circ}\right.$ a $\left.315^{\circ}\right)$. As ocorrências foram agrupadas de acordo com sua exposição, determinando qual apresenta maior suscetibilidade aos incêndios.

Os dados foram organizados também de acordo com as informações contidas (cobertura, hora e data), a fim de se determinar qual a época, horário e tipo de vegetação mais atingida.

\section{RESULTADOS}

De acordo com os dados, foram registradas, dentro do período de estudo, 2.194 ocorrências de incêndios em Juiz de Fora e 632 ocorrências em Ubá, com uma média de 0,86 ocorrências por dia em Juiz de Fora e 0,25 ocorrências por dia em Ubá. Com relação à densidade de ocorrências por área, Juiz de Fora apresentou 5,42 ocorrências $/ \mathrm{km}^{2}$, enquanto Ubá, 2,69 ocorrências $/ \mathrm{km}^{2}$.

Os dois municípios apresentaram maior concentração de ocorrências entre os meses de junho e outubro (Figura 2), concentrando Ubá 85\% dos incêndios neste período e Juiz de Fora $83 \%$.
Com relação à distribuição diária, tanto Juiz de Fora quanto Ubá apresentaram maior número de ocorrências entre 12 e 20 horas (Figura 3), concentrando Juiz de Fora 76\% das ocorrências neste horário e Ubá 77\%, sendo que Juiz de Fora atinge seu pico entre 15 e 16 horas, enquanto que em Ubá o valor máximo é atingido entre 14 e 15 horas.

As áreas queimadas nos dois municípios (Figura 4) apontam para maior incidência de

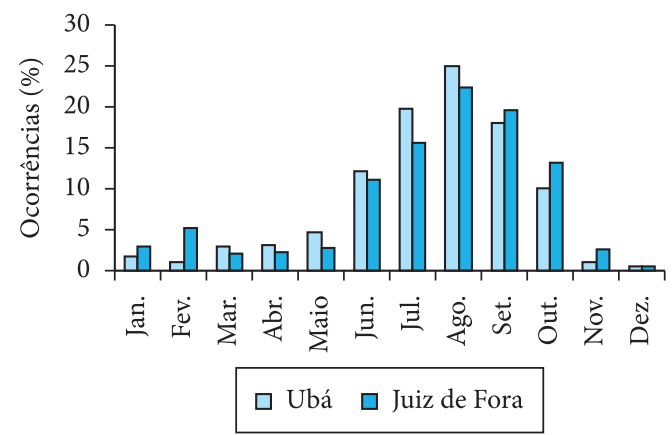

Figura 2. Porcentagens de ocorrências por mês.

Figure 2. Percentages of monthly occurrences.

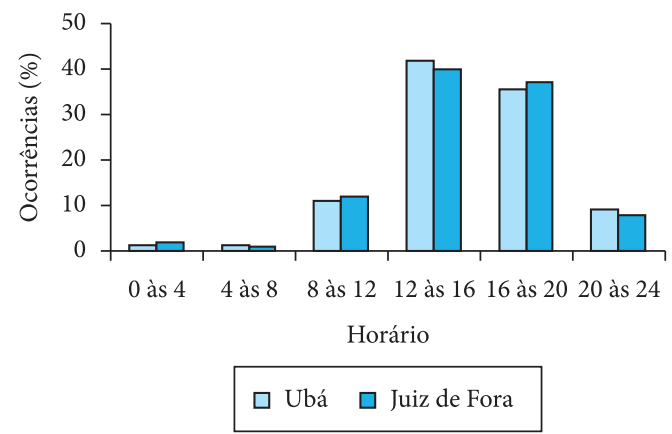

Figura 3. Porcentagens de ocorrências por hora do dia. Figure 3. Percentages of occurrences for hour of the day.

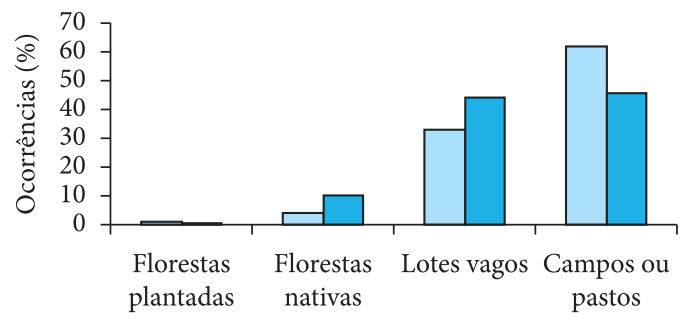

Cobertura

$$
\square \text { Ubá } \square \text { Juiz de Fora }
$$

Figura 4. Ocorrências de incêndios de acordo com o material combustível.

Figure 4. Occurrences of fires in agreement with the combustible material. 
ocorrências em áreas de campos ou pastos e lotes vagos, sendo que, em Juiz de Fora, $89,43 \%$ dos incêndios ocorreram nestas áreas e, em Ubá, 90,24\%.

Analisando-se a exposição das vertentes das ocorrências (Figura 5), tanto Juiz de Fora quanto Ubá concentram maior número de incêndios nas vertentes voltadas para o Norte, seguida das vertentes Oeste, Leste e Sul apresentando menor número de ocorrências nos dois municípios.

\section{DISCUSSÃO}

A maior incidência de incêndios por dia e por $\mathrm{km}^{2}$ de Juiz de Fora em relação à Ubá pode estar relacionada ao tamanho da área e à quantidade de população, visto que, de acordo com Soares e Cordeiro (1974), Soares e Santos (2002), Bonfim et al. (2003) e Santos et al. (2006), a principal causa dos incêndios é a atividade antrópica, como fumantes, queimas para limpeza, incendiários e fogos de recreação. Corroborando, a densidade populacional da área estudada em Juiz de Fora é de aproximadamente $1.125 \mathrm{hab} / \mathrm{km}^{2}$ contra $340 \mathrm{hab} /$ $\mathrm{km}^{2}$ da área estudada em Ubá, mesmo que em Juiz de Fora só tenha se considerado a área urbana do distrito sede e em Ubá tanto a área urbana quanto a área rural do distrito sede. A maior área de estudo em Juiz de Fora, também representa um maior número de vias de acesso como estradas e rodovias onde, de acordo com Lima (2000), grande parte dos incêndios tem seu início em suas margens.

A concentração das ocorrências nos dois municípios entre junho e outubro (Figura 2), é

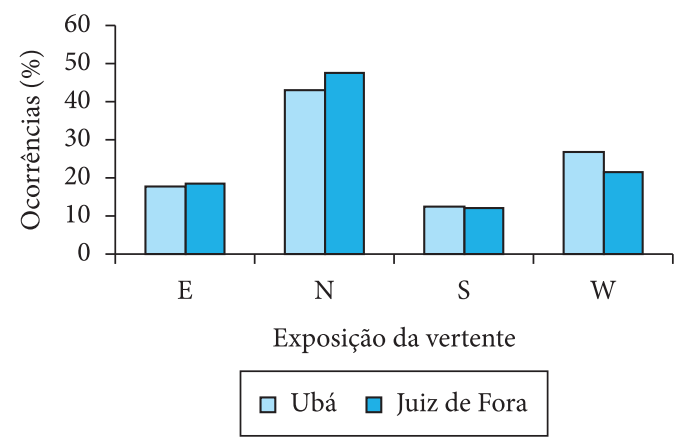

Figura 5. Ocorrências de incêndios de acordo com a exposição da vertente.

Figure 5. Occurrences of fires in agreement with the exhibition of the slope. similar aos encontrados por Soares e Santos (2002) e Santos et al. (2006) para todo o País, mostrando que, efetivamente, o problema dos incêndios se concentra no inverno e início da primavera, devido à maior insolação e evaporação e menor umidade relativa do ar e precipitação (Torres et al., 2008), que favorecem as ocorrências. Além disso, segundo Soares e Santos (2002), é nesta época que os agricultores fazem as queimas para preparo do terreno e limpeza das pastagens.

Os picos de ocorrências de incêndios em agosto e setembro, em Juiz de Fora, coincidem com os picos de produção de serapilheira em florestas estacionais semideciduais (Martins e Rodrigues, 1999). Com isso, além do acúmulo de material combustível no solo, há uma aceleração do processo de secagem desse material com a abertura do dossel, provocado pela queda da folhagem, que favorece a penetração da luz solar, evidenciado pela maior porcentagem de ocorrências em formações florestais de Juiz de Fora, comparado com Ubá (Figura 4).

Com relação ao horário de maior concentração de ocorrências (Figura 3), o cenário climático do período de maior ganho energético (12 às 16 horas) implica uma maior insolação, maior temperatura e menor umidade relativa do ar, favorecendo as ocorrências de incêndios.

Por outro lado, a temperatura mínima do dia é alcançada instantes antes do primeiro raio solar, o que, dependendo da época do ano ocorre por volta das 6 horas (Torres e Machado, 2008), implicando uma maior umidade relativa do ar, resultando em um número mínimo de ocorrências neste período.

Apesar do comportamento similar entre os dois municípios, Ubá atinge o pico de ocorrências uma hora antes de Juiz de Fora, isto pode se justificar pela maior temperatura do município de Ubá que está à cerca de $340 \mathrm{~m}$ mais baixo que Juiz de Fora em relação ao nível do mar. Esta diferença pode representar, segundo Torres e Machado (2008), um aumento de quase $2{ }^{\circ} \mathrm{C}$ na temperatura média do município, e esse fator reflete, ainda de acordo com os autores, na umidade relativa do ar, sendo essa inversamente proporcional à temperatura, tendendo a atingir um valor crítico mais cedo em Ubá. Isto pode ser observado também, na maior diferença entre a quantidade de ocorrências entre as duas faixas 
de horários mais críticos (12 às 16 e 16 às 20 horas) de Ubá em relação à Juiz de Fora (Figura 3).

Analisando-se a cobertura incendiada (Figura 4), a vegetação mais arbórea tende a manter melhor a umidade em relação às herbáceas. Nos lotes vagos distribuídos pelas áreas urbanas, prevalece a vegetação herbácea como as dos campos ou pastos. O tipo de material e seu arranjo facilitam a ignição e propagação do fogo. O material mais fino, por apresentar menor temperatura de ignição e perder mais rapidamente sua umidade (Nunes et al., 2006), facilita o início do incêndio e acelera sua propagação.

Ainda de acordo com os autores, a distribuição uniforme e proximidade das partículas de combustível facilitam a propagação, também favorecendo a ocorrência de incêndios sobre os campos ou pastos e lotes vagos.

Por outro lado, as florestas ou matas, segundo Nunes et al. (2008), interceptam a radiação solar, reduzindo a temperatura do ar e do material combustível no seu interior. Elas também funcionam como uma barreira, evitando a livre passagem de correntes de ar, reduzindo a velocidade do vento em seu interior. Isso diminui a evaporação, dificultando a secagem do material combustível. Além disso, a transpiração do material florestal proporciona um aumento da umidade relativa do ar na área florestada.

A maior quantidade de loteamentos em Juiz de Fora, faz com que se tenha um percentual similar entre as ocorrências em campos ou pastos e lotes vagos, por outro lado, em Ubá, existe um número menor de loteamentos, aumentando a incidência sobre campos ou pastos e diminuindo-a sobre lotes vagos.

Com relação à exposição das vertentes das ocorrências (Figura 5), Hugget (1995), destaca que, no Hemisfério Sul, encostas orientadas para o Norte recebem maior insolação do que as voltadas para o Sul, que, por sua vez, recebem maiores precipitações devido aos ventos carregados de umidade vindos do mar (SW, S e SE). Oliveira et al. (1995), em estudos conduzidos no Maciço da Tijuca, encontraram diferenças significativas para as duas vertentes no que diz respeito a parâmetros como temperatura, precipitação e umidade. Segundo esses autores, as encostas voltadas para o Sul possuem serapilheira em média $41,9 \%$ mais úmida que as voltadas para o
Norte. Além disso, esses autores ainda afirmam que a perda desta umidade também se dá muito mais rápido nas encostas voltadas para o Norte, pois as voltadas para o Sul retém a umidade 1,6 vezes mais que as para o Norte. Consequentemente, a umidade do solo se comporta da mesma maneira, apenas variando de acordo com o tipo de cobertura vegetal à que está associada.

Esta variação de umidade se reflete basicamente em função dos diferentes índices de temperatura destes dois tipos de encosta, visto que as encostas voltadas para o Norte são significativamente mais quentes, devido à maior incidência de calor que as voltadas para o Sul, com $98 \%$ de ocorrência de temperaturas máximas naquelas encostas. As temperaturas mínimas também ocorrem em grande maioria nas encostas norte (86\%), o que deve ser atribuído à maior umidade relativa nas do sul, face ao maior período de deposição de orvalho que atua como um efeito "tampão" reduzindo as temperaturas extremas (Oliveira et al., 1995).

\section{CONCLUSÕES}

De acordo com os resultados pode-se concluir que:

- O tamanho da área de estudo, a densidade populacional e o maior número de vias de acesso resultaram em um maior número de ocorrências por dia e por $\mathrm{km}^{2} \mathrm{em}$ Juiz de Fora em relação à Ubá;

- Os meses de junho, julho, agosto, setembro e outubro foram os que registraram maior número de ocorrências, sendo o mês de agosto o mais problemático para as duas áreas;

- Os horários entre 12 e 16 horas concentraram o maior número de ocorrências em ambas as áreas;

- A maior temperatura do ar, consequentemente menor umidade relativa do ar, proporcionaram um horário de pico de ocorrências mais cedo em Ubá, quando comparado com Juiz de Fora;

- Áreas com vegetação aberta apresentaram maior número de ocorrências;

- A exposição da vertente influencia diretamente nas ocorrências de incêndios em vegetação; e

- Encostas voltadas para o Norte, com vegetação campestre em áreas de maior atuação antrópica proporcionam um maior número de ocorrências. 


\section{STATUS DA SUBMISSÃO}

Recebido: 07/06/2009

\section{AUTOR(ES) PARA CORRESPONDÊNCIA}

\section{Fillipe Tamiozzo Pereira Torres}

Departamento de Engenharia Florestal, Universidade Federal de Viçosa - UFV,

Av. Peter Henry Rolfs, s/n,

Campus Universitário, CEP 36570-000, Viçosa, MG, Brasil

Faculdade de Filosofia, Ciências e Letras, Universidade Presidente Antônio Carlos UNIPAC, Campus II,

Rua Lincoln Rodrigues Costa, 165, CEP 36500-000, Boa Vista, Ubá, MG, Brasil

e-mail: torresftp@yahoo.com.br

\section{REFERENCIAS}

Batista AC. Avaliação da queima controlada em povoamentos de Pinus taeda L. no norte do Paraná [tese]. Curitiba: Setor de Ciências Agrárias, Universidade Federal do Paraná; 1995.

Bonfim VR, Ribeiro GA, Silva E. Diagnóstico do uso do fogo no entorno do Parque Estadual da Serra do Brigadeiro (PESB), MG. Revista Árvore 2003; 27(1):8794.

Fiedler NC, Rodrigues TO, Medeiros MB. Avaliação das condições de trabalho, treinamento, saúde e segurança de brigadistas de combate a incêndios florestais em unidades de conservação do Distrito Federal: estudo de caso. Revista Árvore 2006; 30(1):55-63.

Hugget RJ. Geoecology: an evaluation approach. Londres: Ed. London; 1995.

Instituto Brasileiro de Geografia e Estatística - IBGE. Vocabulário básico de recursos naturais e meio ambiente. Rio de Janeiro: IBGE; 2004.

Lima GS. A prevenção de incêndios florestais no estado de Minas Gerais. Floresta 2000; 30:37-43.
Martins SVE, Rodrigues RR. Produção de serapilheira em clareiras de uma floresta estacional semidecidual no município de Campinas, SP. Revista Botânica Brasileira 1999; 22(3):405-412.

Nunes JRS, Beutling A, Koproski LP, Melo LAN, Biondi D, Batista AC. Relação entre a qualidade da paisagem e o risco de incêndios florestais. Floresta 2008; $38(1): 145-154$.

Nunes JRS, Soares RVE, Batista AC. FMA+ - Um novo índice de perigo de incêndios florestais para o Estado do Paraná, Brasil. Floresta 2006; 36(1):75-91.

Oliveira RR, Zaú AS, Lima DF, Sila MBR, Vianna MC, Sodré DO et al. Significado ecológico da orientação de encostas no Maciço da Tijuca. Oecologia Brasiliensis 1995 ; $1: 523-541$.

Ribeiro GA, Bonfim VR. Incêndio florestal versus queima controlada. Revista Ação Ambiental 2000; 2(12):8-11.

Rizzini CT. Tratado de fitogeografia do Brasil. São Paulo: Universidade de São Paulo; 1979. v. 2; 374 p.

Santos JF, Soares RV, Batista AC. Evolução do perfil dos incêndios florestais em áreas protegidas no Brasil, de 1993 a 2002. Floresta 2006; 36(1):93-100.

Silva JC, Fiedler NC, Ribeiro GA, Silva Júnior, MC. Avaliação de brigadas de incêndios florestais em unidades de conservação. Revista Árvore 2003; 27(1):95101.

Soares RV, Cordeiro L. Análise das causas e épocas de incêndios florestais na região centro-paranaense. Floresta 1974; 5(1):46-49.

Soares RV. Queimas controladas: pós e contras. In Anais do I Fórum Nacional Sobre Incêndios Florestais; 1995; Piracicaba. Piracicaba: IPEF; 1995. p. 6-10.

Soares, RV, Santos JF. Perfil dos incêndios florestais no Brasil de 1994 a 1997. Floresta 2002; 32(2):219-232.

Torres FTP, Machado PJO. Introdução à climatologia. Ubá: Ed. Geographica; 2008.

Torres FTP, Ribeiro GA, Martins SV, Lima GS, Rocha GC. Incêndios em vegetação na área urbana de Juiz de Fora - Minas Gerais. Ubá: Ed. Geographica; 2008. 94 p. 